\title{
PENGARUH PROGAM BOARDING SCHOOL TERHADAP PRESTASI BELAJAR SANTRI SMP IT IHSAN BOARDING SCHOOL RIAU
}

\author{
Robi'ah $^{1}$, Sumarno ${ }^{2}$, Melda Diana ${ }^{3}$, Faisal Musa ${ }^{4}$ \\ ${ }^{1}$ Sekolah Tinggi Agama Islam Negeri (STAIN) Bengkalis \\ ${ }^{2}$ Sekolah Tinggi Ilmu Tarbiyah (STIT) Mumtaz Karimun \\ ${ }^{3,4}$ Sekolah Tinggi Agama Islam Negeri (STAIN) Mandailing Natal \\ E-mail: robiaah07@gmail.com; ; elmuhdan@gmail.com²; \\ meldadiananasution@gmail.com ${ }^{3}$; moesa_123@yahoo.com ${ }^{4}$ \\ Website : https://jurnal.uin-antasari.ac.id/index.php/ptkpend/index \\ Received: 9 Juli 2020; Accepted: 21 Juli 2020; Published: 27 Juli 2020
}

\begin{abstract}
The aim of research for effect learn boarding school with learning outcome student. Research of method quantitatif with statistic deskriptif and analys corelasi product moment. Table data to show boarding school effect with learning outcome the nominal correlation 0,985 , signification $t$ hitung 30,302 more than 2,048 . Spesific $r$ square 0,981 explain effect variable boarding school with learning outcome $98,1 \%$ and the other factor not control.
\end{abstract}

Key Word: boarding school; learning outcome; santri

\begin{abstract}
ABSTRAK
Penelitian ini betujuan untuk mengetahui bagaimana pengaruh system pembelajaran boarding school terhadap prestasi belajar siswa. Metode penelitian yang digunakan adalah kuantitatif dengan jenis penelitian deskriptif statistik dan metode analisis data yang digunakan adalah korelasi product moment. Data-data yang disajikan dalam penelitian ini menggunakan data primer melalui kuisioner. Hasil penelitian menunjukkan bahwa boarding school berpengaruh terhadap prestasi belajar santri yang ditunjukkan dari koefisien korelasi sebesar 0,985, signifikan di uji t hitung sebesar 30,302 yang lebih besar dari t tabel sebesar 2,048. Nilai $r$ square sebesar 0,981 menjelaskan bahwa pengaruh variabel boarding school terhadap prestasi belajar santri sebesar $98,1 \%$ sedangkan sisanya disebabkan oleh faktor lain yang tidak diteliti.
\end{abstract}

Kata Kunci: boarding school; prestasi belajar; santri

PENDAHULUAN

Kehadiran boarding school merupakan alternatif pendidikan bagi orang tua yang tidak ingin mengalami kegagalan dalam menyekolahkan anaknya (Nata, 2001). Terutama bagi mereka yang dalam satu keluarga tidak hanya suami saja yang bekerja, melainkan istri juga bekerja sehingga anak tidak lagi terkontrol dengan baik. Dalam keadaan tersebut maka boarding school adalah pilihan terbaik untuk menyekolahkan anak-anak mereka, dengan maksud agar anak mendapatkan pendidikannya yang sempurna (Badruzaman, 2014).

Peran orang tua akan digantikan oleh para pengasuh yang mengajar di boarding school, tidak hanya mentransfer ilmu di kelas formal namun ketika berada di asrama juga. Mengontrol ibadah para siswa, mendampingi belajar dan aktifitas keseharian mereka. Sehingga terjalin hubungan harmonis antara para siswa dengan pengasuh atau para pendidik.

Peserta didik tidak hanya mengikuti kegiatan belajar mengajar di 
sekolah formal saja, melainkan juga mengikuti pola pembelajaran di asrama pondok pesantren dengan bimbingan pengasuh pesantren dan dewan asatidz (Badruzaman, 2014). Dengan itu semua maka diharapkan progam boarding school akan mampu menjadi solusi untuk menghasilkan lulusan siswa/santri yang unggul dan berkualitas. Namun kesemuanya itu juga tergantung pada bagaimana penyelenggaraan sistem pendidikan (boarding school), manajemen sekolah, dan manajemen pondok pesantren sebagai asrama para siswa (Hendriyanti, 2014).

Prestasi belajar adalah harapan bagi setiap murid yang sedang mengikuti proses pembelajaran di sekolah serta harapan bagi wali murid dan orang tua. Prestasi itu sendiri ada untuk melihat sejauh mana hasil yang sudah didapat siswa dalam penguasaan tugas-tugas atau materi pelajaran yang diterima dalam waktu tertentu (Sawaludin dkk, 2020). Dan pada umumnya prestasi belajar dinyatakan dalam angka atau huruf untuk membandingkan dengan satu kriteria. Seperti yang saya kemukakan tadi di atas bahwa prestasi di lihat dari aspek kognitif (IQ), afektif (SQ) dan psikomotorik (EQ) (Sawaluddin, 2017). Jadi prestasi merupakan hasil belajar yang didapat dengan baik pada seorang siswa baik dalam pendidikan atau bidang keilmuan juga kepribadian. Hasil belajar yang diharapkan biasanya berupa prestasi belajar yang baik atau optimal (Hamidah dkk, 2019). Namun dalam pencapaian hasil belajar yang baik masih saja mengalami kesulitan dan prestasi yang didapat belum dapat dicapai secara optimal. Dalam peningkatan hasil belajar siswa dipengaruhi oleh banyak faktor (Rizkiani, 2012).

Seluruh pelaku pendidikan yaitu siswa, orang tua dan guru tentu ingin tercapainya sebuah prestasi belajar yang baik (Syah, 2006). Prestasi belajar yang baik adalah salah satu indikator akan keberhasilan proses belajar (Leluhur,
2009). Walaupun kenyataannya tidak semua siswa bisa mendapat prestasi yang baik dan ada siswa yang mendapatkan prestasi belajar yang buruk. Baik buruknya prestasi yang diperoleh siswa dipengaruhi oleh berbagai aspek (Sawaluddin dkk, 2018). Salah satunya adalah aspek progam yang dipakai dalam satu institusi sekolah, misalnya adalah progam boarding school (Sawaluddin \& Sainab, 2019).

Para siswa tidak hanya mendapatkan pelajaran di sekolah saja melainkan akan mendapatkan pelajaran tambahan di asrama, seperti tajwid, nahu, sharaf, bahasa arab, sejarah islam dan muhadatsah yang akan dibimbing oleh para ustadz. Sehingga dengan padatnya jadwal belajar di Boarding School, tidak menutup kemungkinan terbengkalainya pelajaran yang ada di sekolah yang berakibat terjadinya perbedaan antara siswa full day dengan boarding school. Dalam hal belajar dan pembelajaran siswa full day cenderung lebih pintar dari pada siswa boarding. Dan juga siswa boarding ketika di dalam kelas lebih banyak tidurnya daripada yang belajar. Ini di ungkapkan oleh setiap guru yang mengajar di dalam kelas, yang mana terdapat siswa boardingnya.

Ada beberapa faktor yang mempengaruhi prestasi belajar peserta didik, secara garis besar terdiri dari faktor internal dan faktor eksternal (Denden, 2018). Faktor internal adalah faktor-faktor yang berasal dari individu anak itu sendiri yang meliputi: penglihatan, pendengaran, struktur tubuh dan sebagainya, intelegensi, kemampuan belajar, cara belajar, motifasi belajar, sikap, perasaan, minat, kondisi psikis, dan kondisi akibat keadaan sosiokultur (Sawaluddin, 2018). Faktor eksternal adalah faktor-faktor yang berasal dari luar individu seorang anak, yaitu: kurikulum, disiplin sekolah, guru, fasilitas belajar, pengelompokan siswa, sistem sosial, status sosial siswa, interaksi guru dan siswa, keadaan politi ekonomi, keadaan waktu dan tempat atau iklim. 


\section{METODE PENELITIAN Objek/Subjek}

Dalam penelitian ini objek penelitian yang akan diteliti adalah siswa kelas IX SMP IT Ihsan Boarding School Riau. Dengan kriteria anak yang diteliti adalah minimal 2 tahun tinggal dan belajar di asrama.

\section{Teknik Pengambilan Sampel}

Dalam teknik pengambilan sampel, peneliti menggunakan metode Purposive Random Sampling, yang mana peneliti hanya mengambil sample yang dibutuhkan saja secara acak. Dari semua murid yang belajar di SMP IT Ihsan Boarding School Riau, yang diteliti hanyalah murid yang berasrama saja.

\section{Teknik Pengumpulan Data}

Kuesioner adalah pertanyaan terstruktur yang diisi sendiri oleh responden berupa pertanyaan menyangkut fakta dan pendapat responden. Terdapat dua instrument yang digunakan dalam penelitian ini yaitu instrumen progam Boarding School dan instrumen prestasi belajar. Yang mana kuisioner ini berupa skala likert. Dengan skala Likert, maka variabel yang akan diukur dijabarkan menjadi indikator variabel (Sawaluddin, 2018). Kemudian indikator tersebut dijadikan sebagai titik tolak untuk menyusun item-item instrumen yang dapat berupa pernyataan atau pertanyaan. Jawaban setiap item instrumen yang menggunakan skala Likert mempunyai gradasi dari sangat positif sampai negatif, yang dapat berupa kata-kata antara lain, Sangat setuju dengan skor 5, Setuju dengan skor 4, Ragu-ragu dengan skor 3, Tidak setuju dengan skor 2, dan Sangat tidak setuju dengan skor 1 .

\section{Teknik Analisis Data.}

Teknik analisis data adalah suatu cara yang dilakukan untuk mengelolah data agar dihasilkan suatu kesimpulan yang tepat. Dalam penelitian ini peneliti menggunakan analisis korelasi. Karena digunakan untuk menguji hubungan antara 2 (dua) variabel atau lebih, apakah kedua variabel tersebut memang mempunyai hubungan yang signifikan, bagaimana arah hubungan dan seberapa kuat hubungan tersebut. Korelasi adalah suatu bentuk analisis data dalam penelitian yang bertujuan untuk mengetahui kekuatan atau bentuk arah hubungan diantara dua variabel atau lebih dan besar pengaruh yang disebabkan oleh variabel yang satu (variabel bebas) terhadap variabel lainnya (variabel terikat).

\section{HASIL DAN PEMBAHASAN \\ Hasil Penelitian}

\section{a. Analisis Indeks Jawaban Responden Terhadap Variabel Siswa Boarding School}

Siswa Boarding School merupakan penentu berpengaruh atau tidaknya terhadap prestasi belajar. Hasil jawaban dan analisis indeks skor jawaban terhadap variabel kualitas produk dapat di jelaskan sebagai berikut :

Tabel.1 Hasil Tanggapan Responden Terhadap Variabel Boarding School (X1)

\begin{tabular}{|c|c|c|c|c|c|c|c|c|}
\hline \multirow{2}{*}{ No. } & \multirow{2}{*}{ Indikator } & \multicolumn{5}{|c|}{ Skor } & \multirow{2}{*}{ Jumlah } & \multirow{2}{*}{ Indeks } \\
\hline & & SS & $\mathbf{S}$ & KS & TS & STS & & \\
\hline 1. & Saya senang tinggal di asrama & 4 & 11 & 13 & 1 & 1 & 106 & 21,2 \\
\hline 2. & $\begin{array}{l}\text { Saya dipaksa orangtua sekolah } \\
\text { berasarama }\end{array}$ & 4 & 6 & 6 & 9 & 5 & 85 & 17 \\
\hline 3. & $\begin{array}{l}\text { Saya diajari oleh kakak kelas di } \\
\text { asrama }\end{array}$ & 3 & 10 & 12 & 3 & 2 & 99 & 19,8 \\
\hline 4. & Saya menjadi rajin shalat lima waktu & 11 & 17 & 2 & 0 & 0 & 101 & 20,2 \\
\hline 5. & Saya menjadi bisa membaca al qur'an & 17 & 11 & 2 & 0 & 0 & 135 & 27 \\
\hline 6. & Saya banyak menghafal al qur'an & 8 & 15 & 6 & 1 & 0 & 120 & 24 \\
\hline 7. & Saya belajar terus di asrama & 0 & 11 & 18 & 1 & 0 & 100 & 20 \\
\hline 8. & Saya banyak bermain di asrama & 6 & 10 & 10 & 4 & 0 & 108 & 21,6 \\
\hline
\end{tabular}




\begin{tabular}{|l|l|c|c|c|c|c|c|c|}
\hline 9. & $\begin{array}{l}\text { Bila ada tugas saya lebih suka } \\
\text { mengerjakannya di asrama }\end{array}$ & 2 & 9 & 17 & 1 & 1 & 100 & 20 \\
\hline 10. & $\begin{array}{l}\text { Sekolah berasarama adalah keinginan } \\
\text { Saya sendiri }\end{array}$ & 3 & 16 & 5 & 4 & 2 & 104 & 20,8 \\
\hline 11. & $\begin{array}{l}\text { Berasrama tempat paling bagus untuk } \\
\text { belajar }\end{array}$ & 4 & 10 & 15 & 1 & 0 & 107 & 21,4 \\
\hline 12. & Saya tidak betah diasrama & 2 & 2 & 16 & 4 & 6 & 80 & 16 \\
\hline 13. & Saya banyak melanggar diasrama & 3 & 4 & 12 & 7 & 2 & 83 & 16,6 \\
\hline 14. & $\begin{array}{l}\text { Saya menjadi lebih baik ketika } \\
\text { tinggal di asrama }\end{array}$ & 8 & 12 & 9 & 1 & 0 & 117 & 23,4 \\
\hline 15. & $\begin{array}{l}\text { Saya mengetahui banyak hal yang } \\
\text { baru di asrama }\end{array}$ & 13 & 15 & 1 & 0 & 0 & 128 & 25,6 \\
\hline \multicolumn{2}{|}{ Rata-rata } & & & & & & 104,9 & 19,65 \\
\hline
\end{tabular}

Berdasarkan data pada tabel 1 diatas dapat diketahui bahwa sebagian besar santri yang berasrama adalah dengan keinginannya sendiri dan banyak yang menjadi rajin shalat 5 waktu berjama'ah, bisa membaca alqur'an dan mengahafalkannya. Asrama merupakan tempat belajar yang efektif bagi para santri dikarenakan mereka dapat diajari oleh kakak kelas mereka secara langsung dan menjadikan mereka lebih baik dari sebelumnya. Dan sebagian kecil tidak mendapatkan hal yang serupa yaitu berasrama hanya mempengaruhi mereka sedikit saja.

\section{b. Analisis Indeks Jawaban Responden Terhadap Variabel Prestasi belajar santri}

Hasil tanggapan tentang prestasi Siswa Boarding School dapat di jelaskan sebagai berikut :

Tabel 2. Hasil Tanggapan Responden Terhadap Variabel Prestasi (Y1)

\begin{tabular}{|c|l|c|c|c|c|c|c|c|}
\hline \multirow{2}{*}{ No. Indicator } & \multicolumn{1}{|c|}{ Skor } & \multicolumn{2}{|c|}{ Jumlah } & \multirow{2}{*}{ Indeks } \\
\cline { 2 - 7 } 1. & Saya selalu siap dalam menerima pelajaran & 4 & 17 & 9 & 0 & 0 & 115 & 23 \\
\hline 2. & $\begin{array}{l}\text { Saya selalu berusaha apabila saya gagal } \\
\text { dalam meraih sebuah prestasi }\end{array}$ & 5 & 13 & 10 & 2 & 0 & 111 & 22,2 \\
\hline 3. & $\begin{array}{l}\text { Saya selalu mengikuti mata pelajaran } \\
\text { dengan kondisi yang tidak terpaksa }\end{array}$ & 4 & 19 & 7 & 0 & 0 & 117 & 23,4 \\
\hline 4. & $\begin{array}{l}\text { Saya mendapatkan pengarahan yang jelas } \\
\text { tentang masa depan atau cita-cita }\end{array}$ & 5 & 17 & 7 & 1 & 0 & 122 & 24,4 \\
\hline 5. & $\begin{array}{l}\text { Saya disadarkan alangkah pentingnya } \\
\text { prestasi untuk meraih cita-cita. }\end{array}$ & 10 & 16 & 3 & 0 & 1 & 124 & 24,8 \\
\hline 6. & $\begin{array}{l}\text { Saya tidak suka membolos ketika pelajaran } \\
\text { dimulai }\end{array}$ & 8 & 10 & 9 & 1 & 2 & 111 & 22,2 \\
\hline 7. & $\begin{array}{l}\text { Saya menyelesaikan tugas yang diberikan } \\
\text { guru dengan baik dan benar }\end{array}$ & 3 & 16 & 11 & 0 & 0 & 112 & 22,4 \\
\hline 8. & $\begin{array}{l}\text { Jika saya mendapat nilai jelek saya selalu } \\
\text { ingin memperbaikinya }\end{array}$ & 9 & 14 & 7 & 0 & 0 & 122 & 24,4 \\
\hline 9. & $\begin{array}{l}\text { Saya selalu cepat dalam menjawab } \\
\text { pertanyaan }\end{array}$ & 1 & 6 & 17 & 5 & 0 & 90 & 18 \\
\hline 10. & $\begin{array}{l}\text { Saya senang membaca pelajaran sendiri } \\
\text { meski belum diajarkan guru }\end{array}$ & 1 & 4 & 21 & 4 & 0 & 92 & 18,4 \\
\hline 11. & $\begin{array}{l}\text { Saya selalu mendapatkan ide setelah } \\
\text { mendapatkan materi baru }\end{array}$ & 2 & 9 & 15 & 4 & 0 & 99 & 19,8 \\
\hline 12. & $\begin{array}{l}\text { Saya selalu mempergunakan kesempatan } \\
\text { untuk bertanya kepada guru }\end{array}$ & 3 & 12 & 11 & 3 & 0 & 105 & 21 \\
\hline
\end{tabular}




\begin{tabular}{|c|l|c|c|c|c|c|c|c|}
\hline 13. & $\begin{array}{l}\text { Saya senang apabila mendapatkan prestasi } \\
\text { yang bagus }\end{array}$ & 17 & 13 & 0 & 0 & 0 & 137 & 27,4 \\
\hline 14. & $\begin{array}{l}\text { Apabila tugas yang diberikan sulit, saya } \\
\text { merasa tertantang }\end{array}$ & 3 & 11 & 15 & 0 & 1 & 105 & 21 \\
\hline 15. & $\begin{array}{l}\text { Saya bersungguh-sungguh dalam belajar } \\
\text { agar mendapatkan nilai yang baik }\end{array}$ & 8 & 15 & 6 & 0 & 1 & 119 & 23,8 \\
\hline \multicolumn{2}{|}{ Rata-rata } & & & & & & 112,7 & 22,41 \\
\hline
\end{tabular}

Tanggapan

responden sebagaimana pada tabel 4.2 menunjukan bahwa sebagian besar responden memberikan tanggapan setuju (skor 3) terhadap pertanyaan-pertanyaan variabel

\section{Uji Reliabilitas Butir}

Dari tabel dapat diuji memasukkan nilai korelasi kedalam rumus Spearman Brown dengan nilai $r$ hitung $(0,918)$ lebih besar dari $r$ tabel $(0,159)$, maka reliabel. Hasil tersebut menunjukan bahwa semua variabel mempunyai $r$

\section{Analisis Uji Regresi}

Ho : Tidak ada pengaruh yang signifikan antara boarding school dengan prestasi belajar santri.

Setelah mendapatkan nilai $\mathrm{t}$ hitung dan $\mathrm{t}$ tabel maka dapat membandigkan $t$ hitung dan $t$ tabel. Dengan demikian, ternyata $\mathrm{t}$ hitung $=30,302$ $>\mathrm{t}_{\text {tabel }}=2,048$, maka Ho ditolak. Karena $\mathrm{t}$ hitung lebih besar $\mathrm{t}$ tabel. Maka Ho ditolak sehingga Ha diterima. Dengan demikian terdapat pengaruh yang signifikan antara progam Boarding School terhadap prestasi belajar santri Ihsan Boarding School Riau.

\section{Pembahasan}

Uji reliabilitas menunjukan bahwa nilai dari semua konstruk atau variabel lebih besar dari $r$ tabel $(0,159)$ yang berarti bahwa kuesioner yang merupakan indikator-indikator dari variabel tersebut adalah reliable atau handal. Hal tersebut dapat dilihat dari hasil pengujian yang telah dilakukan sebagai berikut: variabel boarding school (X1) dan prestasi belajar santri (Y1) dengan nilai sebesar 0,870.

Uji validitas menunjukkan bahwa nilai $r$ hitung dari masing-masing variabel lebih besar dari $r$ tabel sebesar 0,159 dan tingkat signifikan dari masing-masing prestasi belajar yaitu dengan rata-rata indeks skor sebesar 22,41. Berdasarkan kategori rentang skor, maka rata-rata tersebut berada pada tingkatan skor sedang.

hitung $(0,918)$ yang lebih besar yaitu diatas tabel $(0,159)$, sehingga dapat dikatakan semua konsep pengukur masing-masing variabel dari kuesioner adalah reliabel sehingga untuk selanjutnya item-item pada masing-masing konsep variabel tersebut layak digunakan sebagai alatukur.

Ha : Ada pengaruh yang signifikan antara boarding school dengan prestasi belajar santri

variabel kurang dari 0,05. Dengan hasil pengujian yang telah dilakukan sebagai berikut:

1. Untuk variabel boarding school (X1)

a. Indikator senang dengan kode P1 r hitungnya sebesar 0,331 , Kode P2 sebesar 0,032

b. Indikator sosial dengan kode P3 sebesar 0,397,

c. Indikator belajar dengan kode P4 sebesar 0,277, kode P5 sebesar 0,309, kode P6 sebesar 0,122, kode P7 sebesar 0,661, kode P8 sebesar 0,258, kode P9 sebesar 0,13, kode P10 sebesar 0,032, kode P11 sebesar 0,599, kode P12 sebesar -0,38, kode P13 sebesar 0,028, kode P14 sebesar 0,505 , kode P15 sebesar 0,588

2. Untuk variabel prestasi belajar santri (Y1)

a. Indikator faktor internal dengan kode P16 r hitungnya sebesar 0,679, P17 sebesar 0,657, P18 sebesar 0,405, P19 sebesar 0,272, P20 sebesar 0,353, P21 
sebesar 0,448, P22 sebesar 0,677, P23 sebesar 0,461, P24 sebesar 0,454, P25 sebesar 0,652, P26 sebesar 0,521, P27 sebesar 0,628, P28 sebesar 0,505, P29 sebesar 0,243 dan P30 sebesar 0,511.

Jadi, dapat disimpulkan bahwa masing-masing butir pertanyaan adalah valid. Satu variabel independen yang diuji secara individual yang dominan dalam memengaruhi prestasi belajar Santri Ihsan Boarding School Riau (dengan koefisien $96,23 \%$ ).

Hasil dari uji $\mathrm{t}$ menunjukkan bahwa semua variabel mempunyai signifikan kurang dari 0,05. Dari variabel independen pada penelitian ini, pengaruh yang dominan terhadap variabel dependen adalah boarding school, berarti variabel ini adalah paling penting dalam menentukan prestasi belajar santri pada sekolah. Hal ini juga terlihat pada hasil tanggapan responden terhadap variabel boarding school (tabel 3) yang menunjukkan bahwa sebagian besar responden memberikan tanggapan setuju (skor 3 dan 4) terhadap pertanyaanpertanyaan variabel boarding school. Rata-rata indeks skor jawaban diperoleh sebesar 26,71 dimana berada pada tingkatan skor sedang. Hal ini menunjukkan sebagian besar responden menyatakan setuju dan sangat setuju bahwa boarding school merupakan keistimewaan tambahan yang memenuhi kebutuhan siswa.

Hasil dari korelasi menunjukkan bahwasanya tingkat hubungan antara variabel dependen (X1) dan variabel independen (Y1) terdapat korelasi yang sangat kuat $(0,80-0,100)$ yaitu 0,98 .

Hasil pengujian hipotesis

mendapatkan bahwa variabel boarding school memiliki pengaruh yang signifikan terhadap prestasi belajar santri. Hal ini berarti bahwa siswa akan memilih sekolah

\section{PENUTUP}

Berdasarkan penelitian tentang pengaruh boarding school terhadap dengan boarding school yang baik. Dalam penelitian ini siswa yang menilai bahwa boarding school merupakan solusi yang baik dan sesuai dengan kebutuhan siswa. Hipotesis menunjukkan adanya pengaruh boarding school yang positif dan signifikan terhadap prestasi belajar santri yang dapat didukung oleh hasil penelitian. Hal ini menunjukkan bahwa boarding school sangat membantu dalam proses pembelajaran. Siswa akan membandingkan boarding school dengan sekolah biasa yang lain sehingga siswa dapat menentukan sekolah yang dipilih untuk jangka waktu yang lama.

Hasil penelitian ini mendapatkan bahwa dalam banyak hal karakteristik boarding school sudah sesuai dengan kriteria sebagaimana yang diharapkan oleh siswa, dimana dalam hal ini siswa atau calon siswa akan mengharapkan fitur atau keistimewaan tambahan sekolah yang ada, boarding school merupakan salah satunya.

Melihat dari hasil penelitian terdahulu tentang "Pengaruh Sistem Boarding School Terhadap Pembentukan Karakter Pesarta Didik di Ma'had Darul arqam Muhammadiyah Daerah Garut" oleh Anisa Rizkiani mendapatkan hasil korelasi yang sangat tinggi sebesar 0,969 dan dari hasil uji signifikansi menyatakan adanya hubungan yang signifikan antara progam boarding school terhadap pembentukan karakter peserta didik dan memiliki pengaruh sebanyak 93,8\% sehingga sejalan denga hasil penelitian yang saya lakukan mengenai pengaruh boarding school terhadap prestasi santri hidayatullah batam sebesar 98,1\% . Sedangkan $1,1 \%$ sianya dipengaruhi oleh faktor lain yang tidak diteliti seperti faktor motivasi, peran guru, sosial dan pengaruh intelektual

santri.

prestasi belajar santri, maka diperoleh kesimpulan sebagai berikut:

Hasil penelitian menunjukan bahwa progam boarding school 
berpengaruh terhadap prestasi belajar santri hidayatullah batam yang ditunjukkan dengan koefisien korelasi sebesar 0,985 dan nilai $r$ square sebesar 0,091menjelaskan bahwa pengaruh progam boarding school terhadap prestasi santri sebesar $9,1 \%$ sedangkan sisanya disebabkan oleh faktor lain yang tidak diteliti. Adapun hasil analisis linier yang telah dilakukan pada penelitian ini, didapat persamaan regresi sebagai berikut: $\mathrm{Y}=17,233+0,740 \mathrm{X}$.

Sedangkan indeks jawaban responden pada tebel 4.1 menunjukkan bahwa variabel boarding school mempunyai nilai indeks sebesar 19,62 yang merupakan skor sedang dimana penemuan penelitian atas persepsi penilaian responden. Hasil penelitian dari indeks jawaban responden pada tabel 4.3 menunjukkan bahwa variabel boarding school mempunyai nilai indeks sebesar 26,71 yang merupakan tingkatan skor sedang dan boarding school mempunyai pengaruh yang paling besar yakni terlihat pada hasil analisis regresi linear sederhana sebesar 0,766 dimana temuan penelitian atas persepsi responden menilai sebagian besar responden menyatakan bahwa keistimewaan tambahan pada sekolah SMPIT Ihsan Boarding School Riau adalah progam boarding school. Variabel boarding school (X) memiliki pengaruh positif signifikan terhadap prestasi belajar siswa (Y) dengan nilai regresi 0,766 dan nilai t hitung 30,302.

\section{DAFTAR PUSTAKA}

Badruzaman, Balukia. 2014. Dampak Pesantren Terhadap Pengembangan Ekonomi Desa. Jurnal Perencanaan Wilayah dan Kota B SAPPK V3N3.

Bahri, Syaiful.1994. Prestasi Belajar dan kompetensi guru. Surabaya: Usaha Nasional.

Denden, Sundari. 2008. Perbandingan Prestasi Belajar Antara Siswa Sekolah Dasar Unggulan dan Siswa Sekolah Dasar Non-Unggulan di
Kabupaten Serang. JURNAL, Pendidikan Dasar, Nomor:9.

Hendriyenti. 2014. Pelaksanaan Program Boarding School Dalam Pembinaan Moral Siswa Di SMA Taruna Indonesia Palembang. jurnal TA'DIB, Vol. XIX, No. 02

Khozin 2006. Jejak-jejak Pendidikan Islam di Indonesia. Malang: UMM Press.

Laila Hamidah, Sawaluddin Siregar, Nuraini Nuraini, Kepribadian Guru Pendidikan Agama Islam Menurut Buya Hamka, Tarbiyah: Jurnal Ilmiah Kependidikan e-ISSN: 25488376 Vol. 8 No. 2 Juli - Desember 2019 (135 - 146)

Leluhur, Waris. 2009. Peningkatan Prestasi Belajar Siswa Melalui Cooperative Learning Model Artikulasi dan Evaluasi Bentuk Multiplechocice Mata Pelajaran IPS. Jurnal Ilmiah PROGRESSIF No.6. Vol.17.

Mulyani, Dessy. 2013. Hubungan Kesiapan Belajar Siswa Dengan Prestasi Belajar. Jurnal Ilmiah Konseling Volume 2 Nomor 1.

Nata, Abuddin 2001. Sejarah Pertumbuhan Dan Perkembangan Lembaga-Lembaga Pendidikan Islam Di Indonesia. Jakarta: PT Grasindo.

Paturohman, Irfan. 2012. Peran Pendidikan Pondok Pesantren Dalam Perbaikan Kondisi Keberagamaan di Lingkungannya. Jurnal Tarbawi Vol.1, No.1.

Rizkiani, Anisa. 2012. Pengaruh Sistem Boarding School Terhadap

Pembentukan Karakter Peserta Didik di Ma'had Darul Arqam Muhammdiyah Daerah Garut. Jurnal Pendidikan Universitas Garut, Vol. 06; No. 01.

Sawaluddin Sawaluddin, Koy Sahbuddin Harahap, Muhammad Syaifuddin, Sainab Sainab, Syahrul Akmal Latif, Development of the Potential Senses, Reason, and Heart 
According to the Qur'an and its Application in Learning, Advances in Social Science, Education and Humanities Research, volume 253, 3rd Asian Education Symposium (AES 2018), pp.508-511

Sawaluddin Sawaluddin, Munzir Hitami, Zikri Darussamin, Sainab Sainab, The Potential of the Senses in AlQuran as the Basic Elements of the Human Physic and Its Application in Learning, Advances in Social Science, Education and Humanities Research, volume 261, International Conference on Islamic Education (ICIE 2018), pp. 158-162

Sawaluddin, Koy Sahbudin Harahap, Supardi Ritonga, Muhammad Ramli, Prosedur Pengembangan Evaluasi Pembelajaran Pendidikan Agama Islam, Jurnal Pendidikan Islam Vol. 8 No.3 Januari - Juni 2020, pp.79-94

Sawaluddin, Potensi Indra, Akal, dan Kalbu Menurut Al-Qur'an dan Aplikasinya Dalam Pengembangan Pendidikan Dasar, Pekanbaru: UIN Suska Riau, Disertasi, 2017, pp. 402-404

Sawaluddin,

Sainab,

$\underline{\text { THE }}$

INTELLIGENT MEANING IN

THE QUR'AN: Nalysis Of The Sure

Potential In The Al-Qur'an As A Dimension Of Human Psychic Insaniah, Jurnal Madania: Volume 9 : 2, 2019 (e-ISSN 2620-8210 | pISSN pp. 373-395

Sawaluddin, Sawaluddin. "Konsep Evaluasi Dalam Pembelajaran Pendidikan Islam." Jurnal Pendidikan Agama Islam AlThariqah 3, No. 1 (July 13, 2018): 39. Doi:10.25299/ Althariqah. 2018.Vol3 (1).39-53

Siregar, Syofian. 2013. Metode penelitian Kantitatif dilengkapi dengan perbandingan perhitungan manual dan SPSS. Jakarta: Kencana Prenada Media Group
Suara Hidayatullah "Мепијu Pendidikan bertauhid", edisi khusus 1/2011

Syah, Muhibbin. 2006. Psikologi Pendidikan. Bandung: PT Remaja Rosdakarya.

Willis, Sofyan S (2012) Psikologi Pendidikan. Bandung: cV ALFABETA. 